\title{
Decision Analysis of Entrepreneurial Company'
}

\section{Venture Leasing}

\author{
Meng Wang ${ }^{1,2,3}$, Mu Zhang ${ }^{3}$ \\ ${ }^{1}$ Guizhou Institute for Urban Economics and Development, Guizhou University of Finance and Economics, Guiyang \\ Guizhou 550025, China \\ ${ }^{2}$ Guizhou Institution for Technology Innovation \& Entrepreneurship Investment, Guizhou University of Finance \\ and Economics, Guiyang Guizhou 550025, China \\ ${ }^{3}$ School of Finance, Guizhou University of Finance and Economics, Guiyang Guizhou 550025, China
}

\section{创业企业风险租赁的决策分析}

\author{
王蒙 ${ }^{1,2,3}$, 张目 $^{3}$ \\ 1 贵州财经大学贵州城镇经济与发展研究院, 花溪, 贵阳, 贵州 550025 , 中国 \\ 2贵州财经大学贵州科技创新创业投资研究院，花溪，贵阳，贵州 550025，中国 \\ 3 贵州财经大学金融学院, 花溪, 贵阳, 贵州 550025 , 中国
}

\begin{abstract}
In the process of China's economic development, small and medium-sized enterprises have been an indispensable part of. In the spring tide in the structural adjustment of enterprises, small and medium-sized enterprise is shouldering the important responsibility of the economic development. However, the financing difficulties of small and medium-sized enterprise development are the key to hurdle. "Financing lease and venture investment linkage model" as a high-tech investment in the new situation, gradually developed into a important way to solve enterprise financing difficult. Therefore, this article will be to the financing lease and venture investment linkage model research, analysis of main problems and put forward solutions, thus promotes the growing of small and medium-sized enterprises.
\end{abstract}

Keywords: Venture investment, Risk lease, Financing lease

摘要

创业企业的发展关系着国民经济的发展, 资金是 创业企业的发展动力。风险租赁——将融租赁和风险
投资相结合, 并针对高风险创业企业发展的的新兴融 资模式正快速成长。本文重点分析的是具有高风险代 表的创业企业进行风险租贡决策时所考虑的因素; 首 先根据理论框架按照促进和限制企业采用风险租赁 决策两个方面提出数个假设, 然后利用 logistic 回归 等统计方法得出相关刺激因素, 并结合理论知识, 为 风险租贡在创业企业的应用提出建议。

关键词: 风险租页; 决策分析; Logistic 回归

1. 引言

\section{1 选题背景}

风险租赁作为风险投资和金融租赁的衍生品, 是 国际上发展最迅猛的金融服务产业之一。上世纪 70 年代早期的美国, 风险租赁业务一度兴盛。进入 80 年代, 风险租赁业务更是生机勃勃。我国的融资租赁 业早期是作为银行信贷的一种替代形式出现的, 主要 的功能是解决企业的融资需求, 对租贡金额、租赁期 限、租贡物品均不具有决定权, 是一种被动的业务模 式。在这个阶段, 风险租赁独有的、有利于促进产业 升级和客户业务发展的诸多功能均没有得到充分的 培育和利用, 这些功能包括: 资产管理和处置功能、 咨询服务功能、销售促进功能、投资功能等。

我国风险租赁起步时间不长, 市场的认识程度还 比较低、风险租货往往还停留在类信贷阶段, 为实业 
Risk Analysis and Crisis Response in Big Data Era (RAC-16)

服务的手段比较单一, 这些因素都影响了租赁渗透率 的提高。一些欧美国家的融资租赁已成长为仅次于银 行的第二大融资方式, 我国的融资租赁近年来成长速 度很快, 融资租货对各行各业的渗透率将会逐步提 高。因此, 作为衍生品的风险租赁也会蓬勃发展。

未来, 我国的风险租赁一方面将向纵深发展, 即 为客户提供多种增值服务, 变被动提供融资为主动进 行资产管理; 另一方面, 我国的风险租赁也将实现横 向扩张, 提高在飞机、船舶和大型机械设备以外行业 的渗透率。这就需要风险租赁进行专业化分工, 通过 对行业的精细化运作和管理, 积累细分行业的上下游 客户，实现差异化竞争。尤其在创业企业中，风险租 赁将会拥有不可替代的地位。

我国目前租货渗透率不高的行业比比皆是, 包括 信息技术、基础材料、能源等领域。这些行业可能存 在客户类型分散, 资产单价低等不利于风险租赁业务 发展的情况。独立系租赁公司没有资金优势, 适合承 接单笔金额不高的融资租赁业务, 独立系融资租赁公 司也没有行业限制, 适合通过专业化分工来深入扎根 于细分行业或拓展新兴的融资租赁领域, 带动风险租 货行业的深入发展。

本文研究的风险租赁业务隶属于创业板上市企 业, 据调查, 大多数上市企业会以部分股东权益给予 出租方为代价, 出租方面对的权益风险也是风险租赁 与其他一般租岝的根本区别。所以针对此类创业企 业, 研究的不单单是普通的融资租赁业务, 而是最终 以融资租赁的表现形式表现出来具有高风险的风险 租赁业务, 因此, 后面所提到的风险租赁率即创业企 业的融资租赁率。

\section{2 研究意义}

第一, 风险租赁的发展横向差距大, 但是与欧美 市场差距过大的原因是否仅仅是我国的经济发展水 平不足, 亦或是其他原因尚不可知。本文尝试的主要 问题就是分析风险租赁在中国的创业企业中的应用 受到哪些因素的影响。

第二, 政府加强对银行风险管理, 公布了三个办 法一个指引, 即流动资金贷款管理暂行办法》 、《个 人贷款管理暂行办法》、《固定资产贷款管理暂行 办法》和《项目融资业务指引》。虽然有效控制了银 行业的风险, 但是对创业企业来说却是致命打击, 此 时风险租赁的业务优势得到了充分发挥。由于企业获 得银行贷款的审批更为严格, 流程复杂, 限制较多, 而融资租赁和金融租赁的项目审批速度快, 企业在接 受风险租赁时除了租赁业务外还有附加的投资项目, 此时, 风险租赁的优势一览无余。

\section{3 国内外文献综述}

中国内外学者大多认为风险租赁仅仅是风险租 赁或融资租赁的衍生品, 并未做过多介绍和研究。邱 春杨 (2000) 认为风险租赁的最大特点是租赁对象是 风险资本支持的创业公司或者种子公司 [1]。程建中 (2005) 认为风险租赁是指在成熟的租赁市场上, 在 一笔租赁交易中, 出租人租赁债权加投资方式将设备 租赁给特定的承租人, 出租人通过分别获得租金和股 东权益作为投资回报的一项租赁交易 [2]。赵燕和吴 延坤 (2000) 认为风险租赁只是风险投资的一种模式, 在整个风险投资领域, 从全局、长远来看, 股权投资 应是主流, 但在特定时期, 风险租赁可以适时推行 [3]。张陆洋和 Christopher lane Davis 合著的《美国 风险（创业）投资有限合伙制》 [4]（2005 年）中从 有限合伙制的内在机制分析角度提到了风险投资和 风险租赁的有限合伙制的机制选择, 但是并未重点针 对风险租赁进行论述。但是就中国现今的发展阶段来 说, 创业企业正蓬勃生长, 它们中的一些企业可能是 中国未来的支柱产业, 所以风险租赁当下的非主流地 位必将改变。

\section{2. 实证分析}

\section{1 影响企业选择风险租赁的理论评述}

\subsection{1 促进企业选择融资租赁的因素假设}

（1）企业的发展水平

一旦企业拥有较强的发展水平, 通常来说就需要 庞大的资金支持, 用来运转迅速成长的生产链。根据 融资优序理论, 企业面临融资时, 顺序一般为: 内部 融资——债务融资——权益融资 [5]。此时内部融资 已难以达到融资需求量, 结合了债务融资和权益融资 的 “风险租赁” 开始进入创业企业的视野。

（2）企业的负债率

不对称信息理论认为融资结构可以传达某些信 息。部分学者认为企业的负债率可以为投资者提供一 个私人信息, 结合市场的有效性 (企业越被看好, 债 务融资水平越高), 说明企业的高负债率能够吸引大 量的投资者青睐。

（3）企业的税务情况

税率差别理论认为, 风险租赁存在的主要原因是 承租人可以从融资租赁决策得到不同程度的税收优 惠[6]。在财税[2013]37 号中规定, 融资性售后回租不 再属于现代服务业, 划分为贷款业务, 税率由原先的 $17 \%$ 降到 6\%。因此应交税费越高的企业越倾向于采 用风险租货。 
Risk Analysis and Crisis Response in Big Data Era (RAC-16)

\subsection{2 限制企业选择融资租赁的因素假设}

企业的所有权集中度: 这条假设仅仅试用于中国 现阶段的创业企业，基于中国人独有的 “租不如买” 观点, 一旦所有权过于集中, 决策者不愿意选择风险 租赁的个人观点很容易影响企业的融资决策。因此假 设越高的所有权集中度风险租赁选择可能性越低。

\section{2 数据来源及篮选}

相关数据据来自深圳证券交易所, 本文记录了创 业板所有 506 家上市企业 2016 年发布的 2015 年年度 报告的部分信息。为了分辨企业是否进行了风险租赁 活动, 确定了一些笠选条件, 符合风险租赁的笠选条 件包括:
A. “其他应付款” 中 “一年内到期的非流动负债” 有租赁的租金费用说明;
B. 长期应付款的 “按款项性质列示长期应付款” 有 说明;
C. 现金流量表项目的“支付的其他与筹资活动有关 的现金” 中有 “支付融资租赁租金及服务费” - 项;
D. 与金融工具相关的风险内 “市场风险” 的 “利率 风险”有提及;
E. 其他资产负债表日后事项说明。
F. “租赁情况” 里的 “重大合同及其履行情况” 里 有项目介绍;
G. “现金流”里的 “现金流出” 有业务介绍;
H. 利润表中的 “财务费用” 中会有相应解释;
I. 通过融资租赁租入的固定资产情况有列表说明;

上述条件若符合其中一条即可确定此公司进行 了风险租赁业务。经过篮选, 确定 506 家上市企业中 有 81 家进行了风险租赁业务。

\subsection{Logistic 回归分析}

\subsection{1 变量的选取}

根据财务报表分析企业的经营状况，本文选取 了四项指标：应收税率、资产负债率、营业增长率和 前十大股东的持股比例。

鉴于目标变量 (是否采用风险租赁) 是一个二维的虚 拟变量, 本节将利用 logistic 回归对样本数据进行 分析。
本文采取的回归模型为:

$$
\operatorname{Logit}(p)=b_{0}+b_{1} Y F+b_{2} Z C+b_{3} Y Y+b_{4} Q S
$$

其中:

$P$ : 企业采用风险租赁的概率。 $P$ 为 0 代表企业无风 险租赁业务, $P$ 为 1 代表企业采取了风险租赁;

b0: 回归方程常数项;

bi：各解释变量系数, i=1, 2, 3, 4;

YF：应付税率，反应企业纳税情况;

ZC：资产负债率，反映企业的偿债水平;

$\mathrm{YY}$ ：营业增长率，反应企业发展能力;

QS：前十大股东的持股比例，反映企业所有权结构。 在史晓军的《Logistic 违约率模型最优样本配 比与分界点的模拟分析》 [7] 中提到 Logistic 模型是 研究违约率的主流方法之一, 通过实证比较的方法得 出 $1: 3$ 的样本配比与 0 . 647 的临界点比较适合我国 的情况。由于违约率问题与融资租赁问题类似, 均为 “yes or no” 的二元 logistic 问题,

本文设置了三种样本配比模式, 分别为“ 1 比 5 ”、 “1 比 4”、“1 比 3”（注: 配比比率仅为近似数）, 在得到相关统计结果后判断这三种模式的适用性。

\subsection{2 “1 比 5” 配比模式下的 logistic 回归}

一共 484 家企业, 有 80 家进行风险租贡, 408 家未进行风险租赁。样本配比大约为 $1: 5$, 利用 SPSS 软件的二元 logistic 回归得出表 1 中的结果, 模型 整体拟合度通过了显著性检验。

表 1 模型系数的显著性检验

\begin{tabular}{ccccc}
\hline & 卡方 & df & Sig. \\
\hline 步骤 1 & 步骤 & 21.335 & 4 & .000 \\
& 块 & 21.335 & 4 & .000 \\
& 模型 & 21.335 & 4 & .000 \\
\hline
\end{tabular}

表 2 设置的置信区间为 95\%, 仅有 “前十大股东 持股比例” 和 “营业收入增长率” 的系数通过了显著 性检验, 显著性分别为 0.000 和 0.051 , 因此拟合的 logistic 回归模型为:

$$
\operatorname{Logit}(p)=0.272+0.005 Y Y-0.035 Q S
$$

表 3 显示的是根据表 2 得出的模型预测 “公司是 否进行风险租赁” 的准确率, 发现预测的准确率为 $83.5 \%$ 。 
Risk Analysis and Crisis Response in Big Data Era (RAC-16)

表 2 各变量回归系数及显著性检验

\begin{tabular}{cccccccccc}
\hline & & & & & & \multicolumn{2}{c}{ EXP(B) 的 95\% C.I. } \\
& B & S.E, & Wals & df & Sig. & Exp (B) & 下限 & 上限 \\
\hline 步骤 $1^{\mathrm{a}}$ & 前十股东持股比例 & -.035 & .010 & 13.070 & 1 & .000 & .965 & .950 & .981 \\
& 资产负债率 & .000 & .001 & .208 & 1 & .648 & 1.000 & .999 & 1.002 \\
应付税率 & .000 & .001 & .341 & 1 & .559 & 1.000 & .999 & 1.001 \\
营业收入增长率 & .005 & .003 & 4.172 & 1 & .041 & 1.005 & 1.001 & 1.010 \\
常量 & .272 & .572 & .226 & 1 & .635 & 1.313 & & \\
\hline
\end{tabular}

表 3 logistic 模型的预测准确率

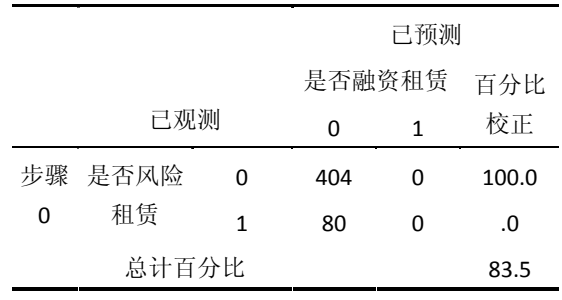

2.3.3 “1 比 4” 配比模式下的 logistic 回归

在 “ 1 比 5 ” 配比模式的基础上随机删减 80 组企 业数据, 为防止企业的所属行业影响最终的模型, 按 比例删选 60 组属于制造业的企业数据, 15 组信息技 术类的企业数据, 以及 5 组其他类型企业数据。此时, 样本中一共 80 家进行风险租赁的企业, 328 家未进 行风险租赁的企业, 总计 408 组样本, 利用 SPSS 软 件, 最终得到表 4 的统计结果。

由表 4 可知, “1 比 4 ” 的样本配比同样通过了 显著性检验。

表 5 设置的置信区间为 95\%，也仅有 “前十大股 东持股比例” 和 “营业收入增长率” 的系数通过了显 著性检验, 显著性分别为 0.000 和 0.033 , “营业收 入增长率” 的显著性较 “ $1: 5$ ” 时略有加强, 得到拟

\begin{tabular}{ccccc} 
& 表 4 & \multicolumn{3}{c}{ 模型系数的显著性检验 } \\
\hline & & 卡方 & $\mathrm{df}$ & Sig. \\
\hline 步骤 1 & 步骤 & 24.990 & 4 & .000 \\
& 块 & 24.990 & 4 & .000 \\
& 模型 & 24.990 & 4 & .000 \\
\hline
\end{tabular}

合的 logistic 回归模型为:

$$
\operatorname{Logit}(p)=0.626+0.001 Y Y-0.038 Q S
$$

表 6 显示的是根据表 5 得出的模型预测 “公司是 否进行风险租赁” 的准确率, 发现预测的准确率为 $80.4 \%$, 对比 “1:5” 的配比模式, 准确率有所降低。

\subsection{4 “1 比 3” 配比模式下的 logistic 回归}

在 “ 1 比 4” 配比模式的基础上随机删减 80 组企 业数据, 删减方式与上一节相同。此时, 样本中一共 80 家进行风险租赁的企业, 248 家未进行风险租赁的 企业, 总计 328 组样本, 利用 SPSS 软件, 最终得到 表 7 的统计结果。“1 比 3 ” 的样本配比同样通过了 显著性检验。

表 5 各变量回归系数及显著性检验

\begin{tabular}{|c|c|c|c|c|c|c|c|c|}
\hline & & & & & & & $\operatorname{EXP}(B)$ 的 & 5\% C.I. \\
\hline & B & S.E, & Wals & df & Sig. & $\operatorname{Exp}(B)$ & 下限 & 上限 \\
\hline 步骤 $1^{\mathrm{a}}$ 应付税率 & .001 & .001 & .864 & 1 & .353 & 1.001 & .999 & 1.00 \\
\hline 资产负债率 & .000 & .001 & .202 & 1 & .653 & 1.000 & .998 & 1.00 \\
\hline 营业收入增长率 & .006 & .003 & 4.543 & 1 & .033 & 1.006 & 1.000 & 1.01 \\
\hline 前十股东持股比例 & -.038 & .010 & 14.289 & 1 & .000 & .963 & .944 & .98 \\
\hline 常量 & .626 & .598 & 1.095 & 1 & .295 & 1.870 & & \\
\hline
\end{tabular}


Risk Analysis and Crisis Response in Big Data Era (RAC-16)

表6. logistic模型的预测准确率

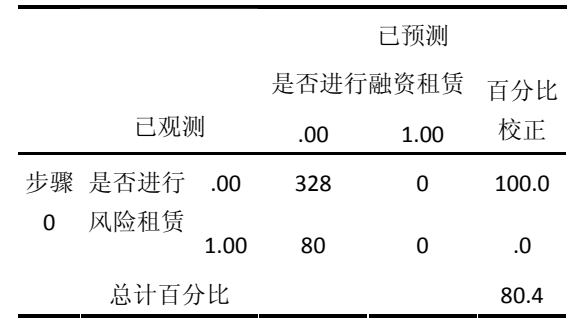

表7. 模型系数的显著性检验

\begin{tabular}{ccccc}
\hline & & 卡方 & df & Sig. \\
\hline 步骤 1 & 步骤 & 27.007 & 4 & .000 \\
& 块 & 27.007 & 4 & .000 \\
& 模型 & 27.007 & 4 & .000 \\
\hline
\end{tabular}

表 8 各变量回归系数及显著性检验

$\operatorname{EXP}(B)$ 的 $95 \%$ C.I.

\begin{tabular}{|c|c|c|c|c|c|c|c|c|c|}
\hline & & B & S.E, & Wals & df & Sig. & $\operatorname{Exp}(B)$ & 下限 & 上限 \\
\hline \multirow[t]{5}{*}{ 步骤 $1^{\mathrm{a}}$} & 应付税率 & .001 & .001 & .641 & 1 & .423 & 1.001 & .999 & 1.002 \\
\hline & 资产负债率 & .000 & .001 & .028 & 1 & .866 & 1.000 & .998 & 1.002 \\
\hline & 营业收入增长率 & .008 & .003 & 6.746 & 1 & .009 & 1.008 & 1.002 & 1.015 \\
\hline & 前十股东持股比例 & -.043 & .011 & 15.600 & 1 & .000 & .958 & .938 & .979 \\
\hline & 常量 & 1.149 & .642 & 3.209 & 1 & .073 & 3.156 & & \\
\hline
\end{tabular}

表 8 设置的置信区间为 95\%，也仅有 “前十大股 最好的模式，即 “1 比 5 ” 的样本配比模式，得到拟 东持股比例” 和 “营业收入增长率”的系数通过了显 著性检验, 显著性分别为 0.011 和 0.001 , “营业收 入增长率” 的显著性较 “ $1: 4$ ” 时略有加强, 得到拟 合的 logistic 回归模型为:

$$
\operatorname{Logit}(p)=1.149+0.008 Y Y-0.043 Q S
$$

表 9 显示的是根据表 8 得出的模型预测的 “公司 是否进行风险租赁” 的准确率, 发现预测的准确率为 $76.2 \%$ 。

表 9 logistic 模型的预测准确率

\begin{tabular}{|c|c|c|c|c|c|}
\hline & \multirow{3}{*}{\multicolumn{2}{|c|}{ 已观测 }} & \multicolumn{3}{|c|}{ 已预测 } \\
\hline & & & \multicolumn{2}{|c|}{ 是否进行融资租赁 } & \multirow{2}{*}{$\begin{array}{c}\text { 百分比 } \\
\text { 校正 }\end{array}$} \\
\hline & & & 0 & 1 & \\
\hline 步骤 & 是否进行风 & 0 & 244 & 4 & 98.4 \\
\hline \multirow[t]{2}{*}{1} & 险租赁 & 1 & 74 & 6 & 7.5 \\
\hline & 总计百分 & & & & 76.2 \\
\hline
\end{tabular}

可以发现, 无论在哪种配比的模式下, 都是只有 “营业收入增长率” 和 “前十大股东的持股比例” 通 过了显著性检验。最大的差别是：“1 比 5 ” 的配比 模式下, 模型的预测准确率为 $83.5 \%$; “1 比 4” 的 配比模式下, 模型的预测准确率为 $80.4 \%$; “1 比 3 ” 的配比模式下, 模型的预测准确率为 $76.2 \%$ 。因此, 在得到同样显著性结果的情况下, 我们选择预测效果
合的 logistic 回归模型:

$$
\operatorname{Logit}(p)=0.272+0.005 Y Y-0.035 Q S
$$

可以发现，与 “违约率问题” 类似，“风险租赁” 问题虽然最优配比数值不同，但是经过验证同样有最 优样本配比模式。本文因样本量限制, 仅能选取到“1 比 5”为止, 因此得到 “1 比 5 ” 最优的结论仅适用 于本文, 其他样本量不一定合适。

\section{3. 结论及建议}

通过 SPSS 统计软件的运算结果, 发现在 “前十 大股东持股比例”、“营业增长率”、“应付税率” 和 “资产负债率” 中仅有前两个因素通过了显著性检 验, 而且, 通过三组不同配比结果得到的模型可以推 断:

（1）企业的发展能力和所有权结构对企业是否通过 风险租赁的决策有决定性的影响;

（2）企业较强的发展能力促进企业选择风险租贡; 企业较集中的所有权结构抑制了企业选择风险租 赁。

（3）本文的数据来源于深圳证券交易所 506 家创业 板上市公司的年度报告, 由于数据庞大、录入过程复 杂, 仅在每一份报表中选取了 16 个数据, 因此只得 到 4 个检验指标。不仅指标体系相对薄弱, 而且创业 
Risk Analysis and Crisis Response in Big Data Era (RAC-16)

板的上市公司不能完全代表所有创业企业, 本文的研 究仅有部分参考价值。

在企业选择风险租赁的促进因素方面并不能提 出针对性意见, 毕竟企业的发展能力不是只言片语就 能提高的, 但是在其他方面有几点建议:

（1）转变“租不如买”的思想, 逐渐接受融资租赁、 风险租赁等新兴融资模式; 接受主流观点, 即设备的 使用远比拥有更重要。基础雄厚的企业可以选择售后 回租的方式得到国家在租赁方面最低的税率优惠, 另 一方面也减缓了企业的现金流压力。

（2）适当降低所有制结构集中度, 避免“一人拍板” 的情况发生，但也不能过于分散决策权。董事会、股 东大会等方式均能在一定程度上削弱个别决策者的 个人想法[8]。

（3）政府应当扩大税率优惠范围。虽然在 2015 年 5 月, 金融保险营改增方案推出后金融业税率降到 6\%, 但是金融租赁和融资租赁所属行业不同导致两者交 集的风险租赁更是行业划分困难。由此导致的不平等 税率一定程度上阻碍了风险租赁在创业企业中的发 展。

（4）大力扶持投资企业, 在源头上提高创业企业中 标概率, 缓减当前“僧多粥少”的情况。

（5）提倡“多对一”的投资模式。风险租赁的风险较 融资租赁高, 较风险投资低, 但是设备购买所需资金 依然庞大, 股权收益率不确定, 此时, 可以联合多家 投资公司联合购买设备, 共同承担风险, 进行风险租 货; 针对发展形势良好的企业, 可以采用风险杜杆租 赁的方式减小投资额。

\section{致谢}

本文为国家自然科学基金地区项目《贷款风险补 偿资金对科技型中小企业信贷配给的影响机理研究》 (71263011)的阶段性成果之一。

\section{4. 参考文献}

[1] 邱春杨.风险租赁：一种投资高技术的新形式.政 策与管理,2000,(5):30-33.

[2] 陈建中. 风险租赁及其在中小企业融资中的运用. 湖南工程学院学报(社会科学版), 2005,(1):1-4.

[3] 赵燕, 吴延坤. 风险租赁: 风险投资的一种重要模 式.科学管理研究,2000,10(5):39-41.

[4] 张陆洋. 美国风险 (创业) 投资有限合伙制[M] 复旦大学出版社, 2005.
[5] L. J. Mintz, S. Isenstein, J. K. Morris, et al. Venture Leasing. 1989.

[6] M.D..Mayer-Fiedrich. Venture Leasing als Finanzinnovation in Deutschland. Physica-Verlag HD, 2005.

[7] 石晓军.Logistic 违约率模型最优样本配比与分 界点的模拟分析. 数理统计与管理, 2006, 25(6):675-682.

[8] M. Zhang and Z.F. Zhou. A credit rating model for enterprises based on projection pursuit and k-means clustering algorithm. Journal of Risk Analysis and Crisis Response,2012, 2(2):131-138. 